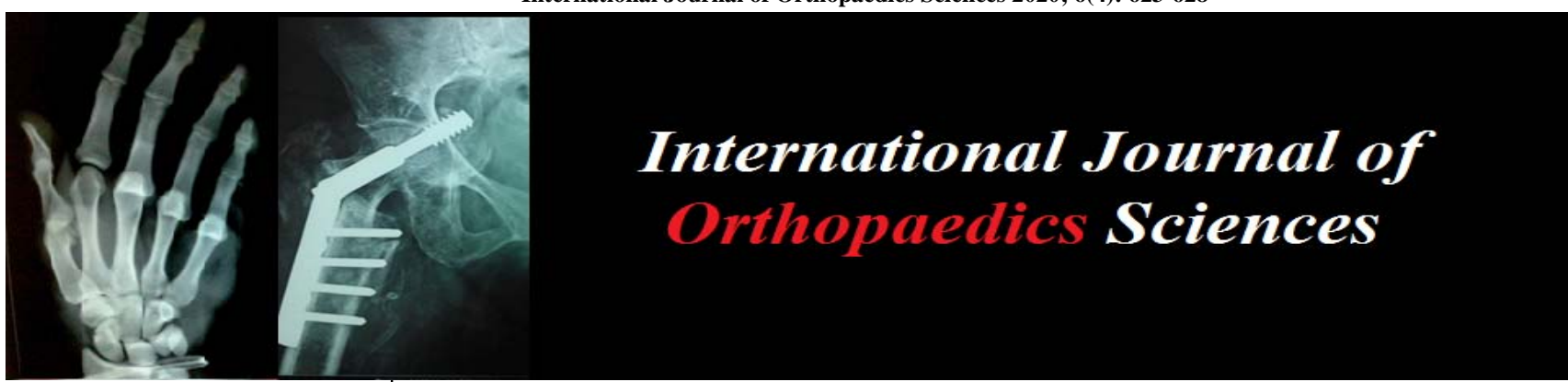

E-ISSN: 2395-1958

P-ISSN: 2706-6630

IJOS 2020; 6(4): 623-628

(C) 2020 IJOS

www.orthopaper.com

Received: 13-08-2020

Accepted: 21-09-2020

Dr. Raju Kulkarni

Associate Professor,

Department of Orthopaedics,

Mahadevappa Rampure Medical College, Kalaburagi, Karnataka, India

Dr. Sunilkumar

Junior Resident,

Department of Orthopaedics,

Mahadevappa Rampure Medical College, Kalaburagi, Karnataka, India
Corresponding Author: Dr. Raju Kulkarni, Associate Professor, Department of Orthopaedics, Mahadevappa Rampure Medical College, Kalaburagi, Karnataka, India

\section{A study of functional and radiological outcome of complex fracutre dislocation of proximal humerus treated with proximal humeral internal locking system (Philos) plate}

\section{Dr. Raju Kulkarni and Dr. Sunilkumar}

DOI: https://doi.org/10.22271/ortho.2020.v6.i4i.2396

\section{Abstract}

Fracture dislocations of the proximal humerus are extremely rare and have poor functional and radiological outcome regardless of many available surgical interventions. There has been a wide variation in optimum modality of treatment of proximal humerus fractures ranging from conservative treatment, open reduction and internal fixation to total and reverse shoulder arthroplasty. We have evaluated the outcome of efficacy of proximal humeral internal locking system (PHILOS) plate in complex fracture dislocation of the proximal humerus. A total of 20 patients with fracture dislocation of proximal humerus were included in the study after careful inclusion and exclusion criteria. All fracture dislocations were fixed with proximal humeral internal locking system (PHILOS) plate and patients were followed up at regular intervals. Final evaluation was done based on Neer's scoring system.

Open reduction and internal fixation of proximal humeral fracture dislocation with the PHILOS plate was associated with good functional and radiological outcomes provided the correct surgical technique was used.

Keywords: proximal humerus, proximal humerus fracture dislocation, PHILOS plate, Neer's scoring system

\section{Introduction}

Proximal humerus fractures accounts for about 4 to $5 \%$ of all fractures ${ }^{[1]}$. They are the third most common fractures in elderly population after hip and distal radius fractures ${ }^{[2]}$. Fracture dislocations of the proximal humerus are rare and have poor functional and radiological outcome regardless of a variety of available surgical interventions ${ }^{[3]}$. Incidence of these fractures increases by $13.7 \%$ per year. Increase in incidence is due to more geriatric population with osteoporotic bone, with an annual incidence of 90-105 fractures per 1 lakh.

Mechanism of injury is fall from standing height with direct impact at the fracture site. Proximal humerus fractures also occurs due to fall from height, road traffic accident and in cases of sports injuries. Fracture dislocations of the proximal humerus usually follows high energy trauma and mandates surgical treatment irrespective of the age.

The treatment goal is to achieve a painless shoulder with full functional outcome. Regarding treatment of proximal humerus fractures controversies still exists whether to do conservative or operative management. Various operative procedures are described for fixation of these fractures like percutaneous pining, tension band wiring, platting, rush nailing, prosthetic replacement by total shoulder replacement and reverse shoulder replacement ${ }^{[4,5]}$.

Recent trend in internal fixation has moved on to locking plates. Proximal humeral internal locking system (PHILOS) a new generation locking plates provides rigid fixation and more angular stability compared to other methods of operative treatment and helps in early mobilization and with added physiotherapy to provide a painless shoulder and good functional outcome. With advancing age and osteoporosis the risk of poor results keeps on increasing irrespective of the modality of treatment ${ }^{[6]}$. All techniques are associated with varying incidence of post-operative stiffness, implant failure, osteonecrosis, non-union, mal-union and rotator cuff weakness. 
Conservative treatment of stable, minimally displaced fractures has consistently given good results. It is the displaced and unstable fractures and those with dislocations that require operative management. Long term results of close reduction and k-wiring have been consistently giving good results probably due to preservation of soft tissue and preserving the vascular supply. ORIF has distinct advantages of anatomical reduction and early mobilization but it also increases the incidence of avascular necrosis, and wound infection ${ }^{[5]}$. Locked plates act as internal-external fixators thereby acting as angle-stable constructs and provide higher pull out strength of locked screws. Final outcome is largely dependent on severity of injury, age, medical condition, activity level, osteoporosis, post-operative rehabilitation programme, use of appropriate locking plates with restoration of rotator cuff anatomy.

\section{Materials \& Methods}

The study was conducted on 20 patients of age between 18 to 85 years were enrolled after detailed clinical and appropriate radiological evaluation in Department of Orthopedics, Mahadevappa Rampure Medical College, Kalaburagi and other Private Hospitals in Kalaburagi. It was conducted between June 2018 to March 2020. All the surgeries were carried out by same surgical team i,e Dr. Raju kulkarni \& Dr. Sunilkumar. Neer's scoring system was used to evaluate the functional outcome.

\section{Inclusion Criteria:}

Age 18 to 80 years.

Displaced fracture dislocation of, 3 part and 4 part fractures.

Medically fit patients.

\section{Exclusion Criteria:}

Undisplaced fractures.

Open injuries.
Pathological fractures.

Other associated fractures.

Pre-existing medical morbidity.

\section{Surgical Technique}

- General anesthesia and/a regional block was used and a beach chair position was given to all the patients.

- An $8 \mathrm{~cm}$ to $10 \mathrm{~cm}$ incision starting from coronoid process was taken along the line of deltopectoral groove. The internervous plane between deltoid and the pectoralis major muscle was identified and separated. The cephalic vein was retracted laterally or medially depending upon the exposure.

- The fracture fragments were identified and the haematoma was cleared off completely. Tag sutures were taken through the rotator cuff muscles for later repair.

- Preliminary relocation and fracture reduction was done with the help of $\mathrm{K}$ wires and checked in both the orthogonal views. PHILOS plate was applied about 5-8 $\mathrm{mm}$ distal to the greater tuberosity and around $2-4 \mathrm{~mm}$ posterior to the bicipital groove. The plate was first fixed to the distal fragment and then screws were inserted in the head as per the woodpecker technique. Final reduction was checked in both the orthogonal views.

- The previously tagged sutures of the rotator cuff were passed through the holes in the plate and sutured. Meticulous closure was done in all the cases.

- Libs are immobilised using arm pouch postoperatively. Mobilization was started from postoperative day three/after drain removed. Similar pain management protocols were followed in all the cases.

- All the patients were assessed at a regular interval of 3,6 and 12 months interval. Clinical assessment was done in the form of pain, function and range of movements. Antero-posterior and axial X-rays were performed for all the patients at each follow up to assess the fracture union.

\section{Case 1}
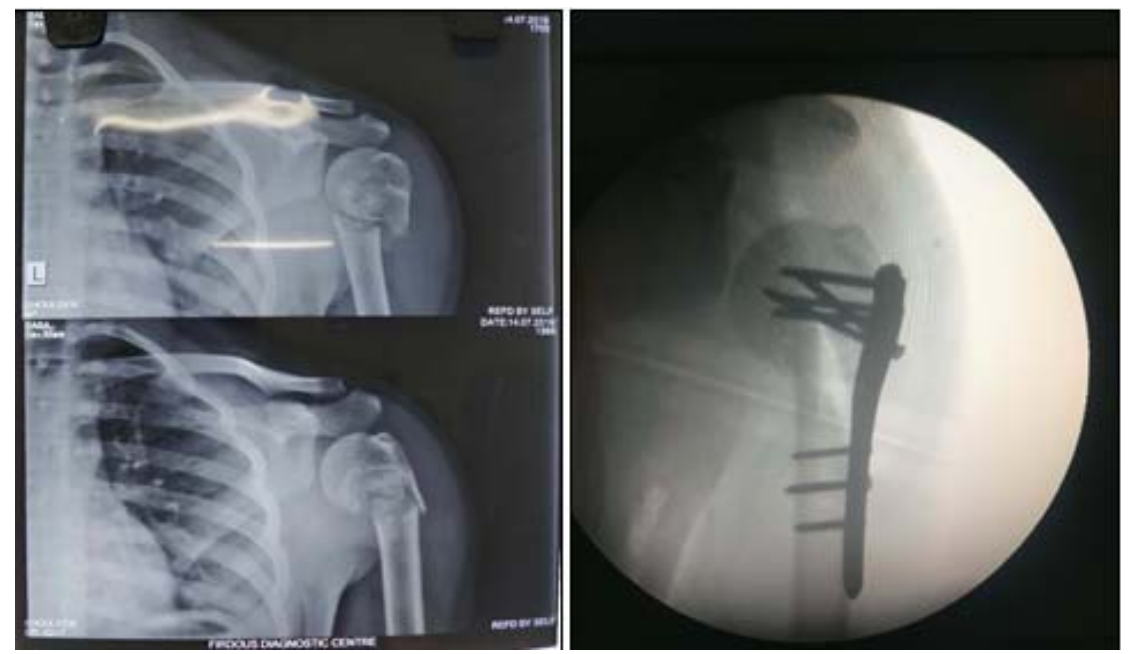


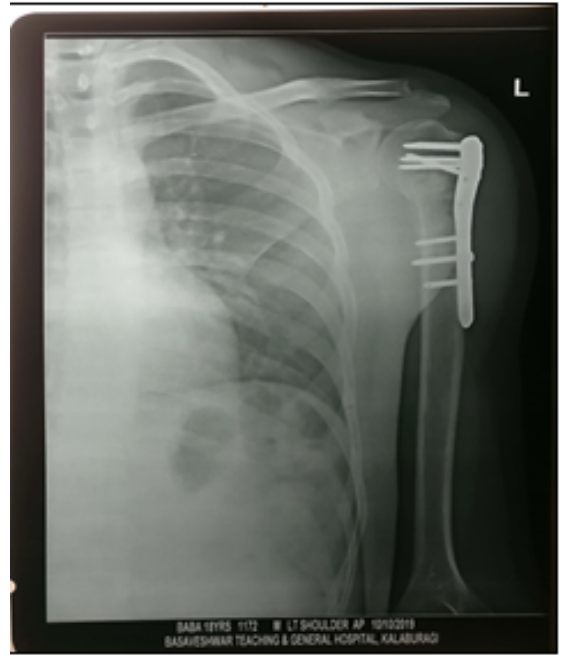

$1^{\text {tt }}$ month follow up x-ray
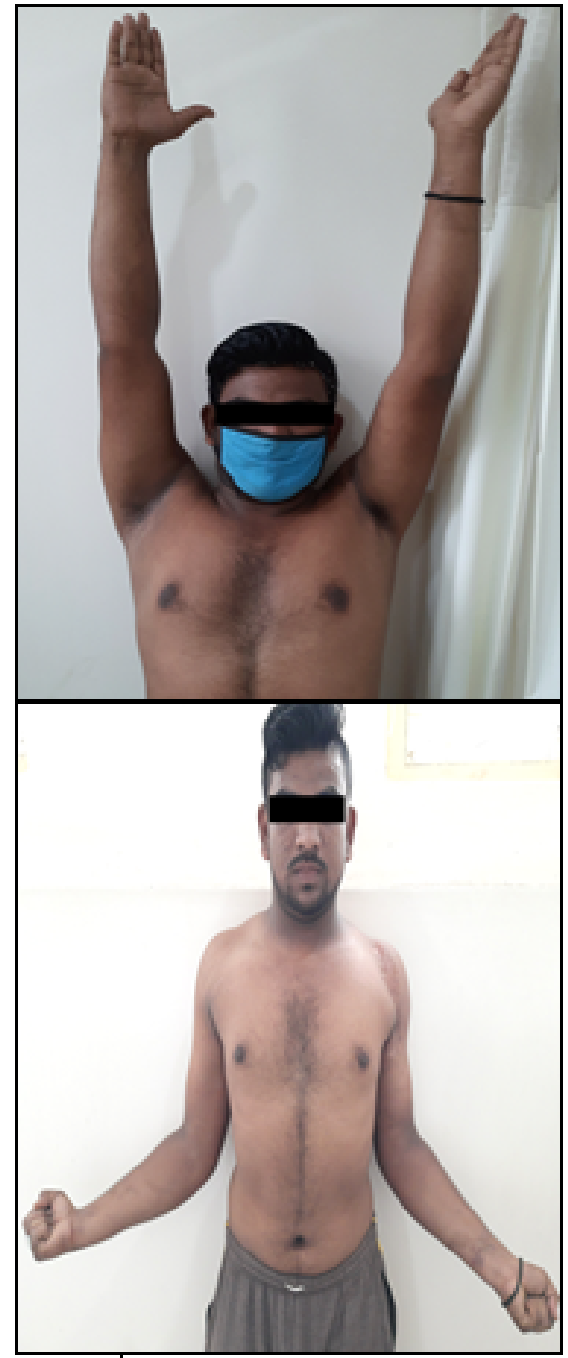

12 month follow up

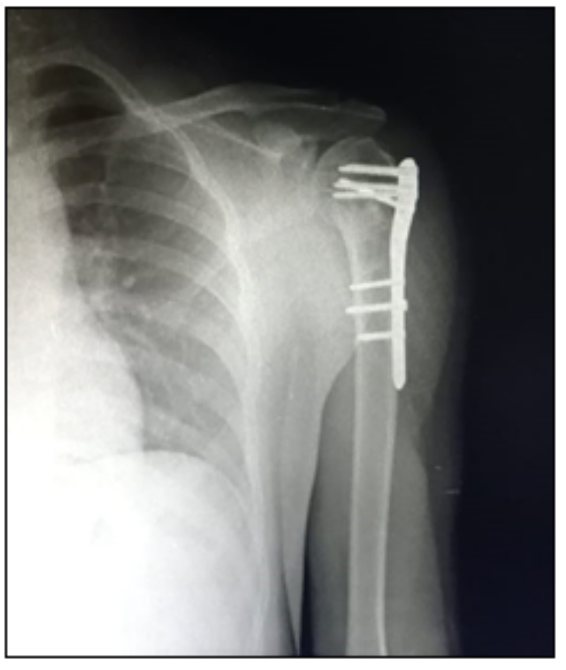

12 month follow up $x$-ray

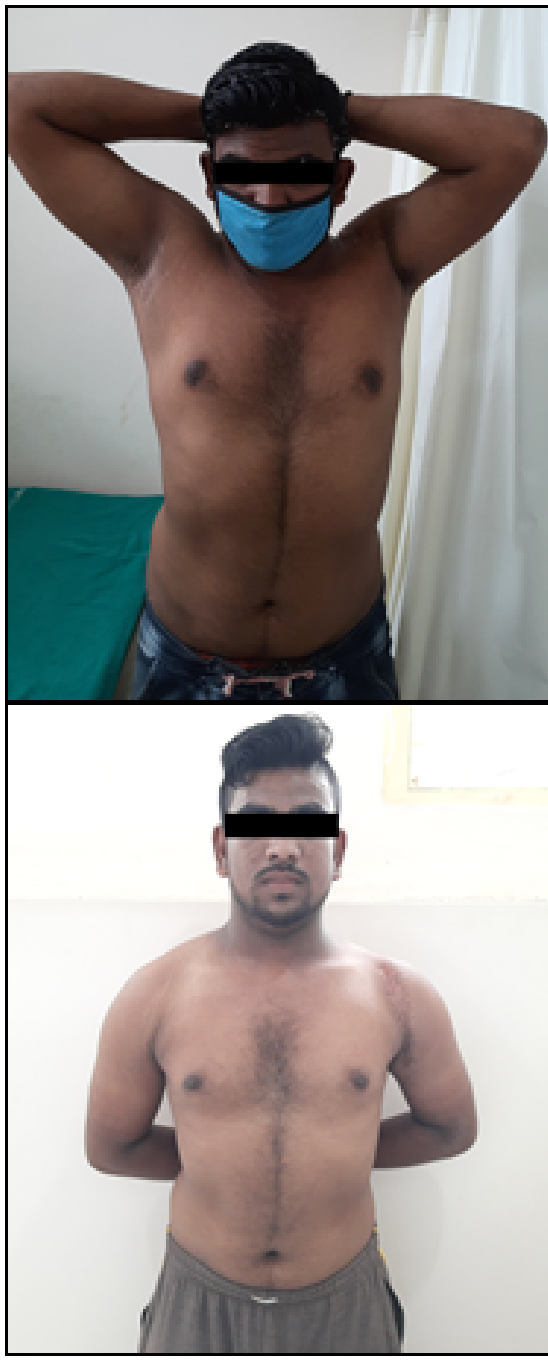

$$
\text { , }
$$




\section{Case 2}

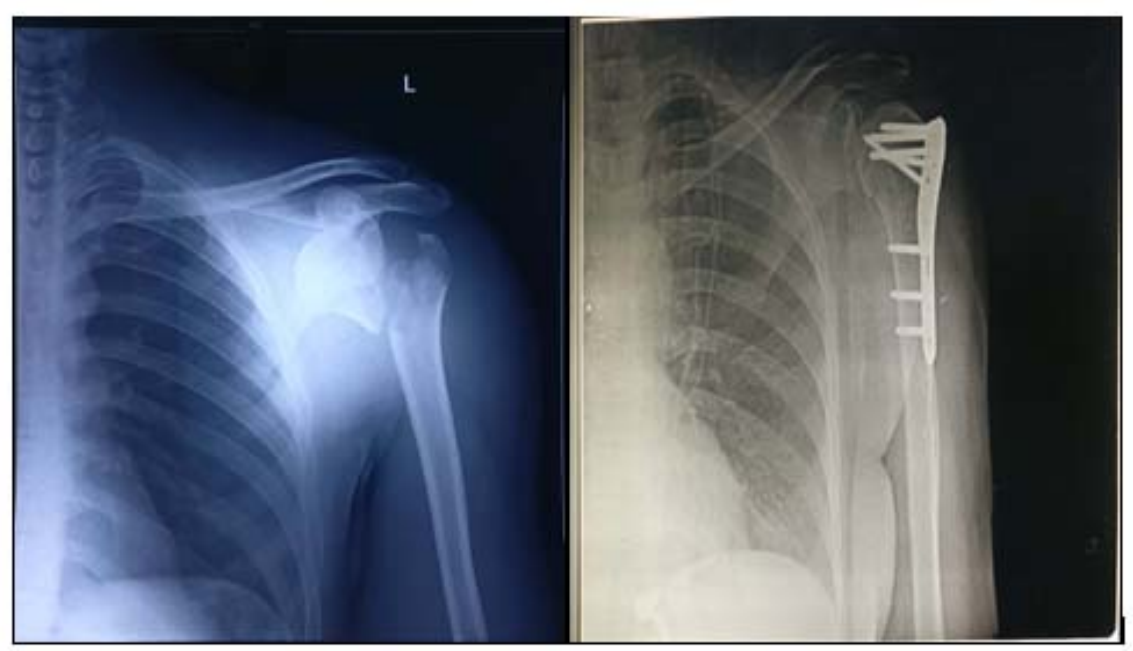

Immediate post op $x$-ray

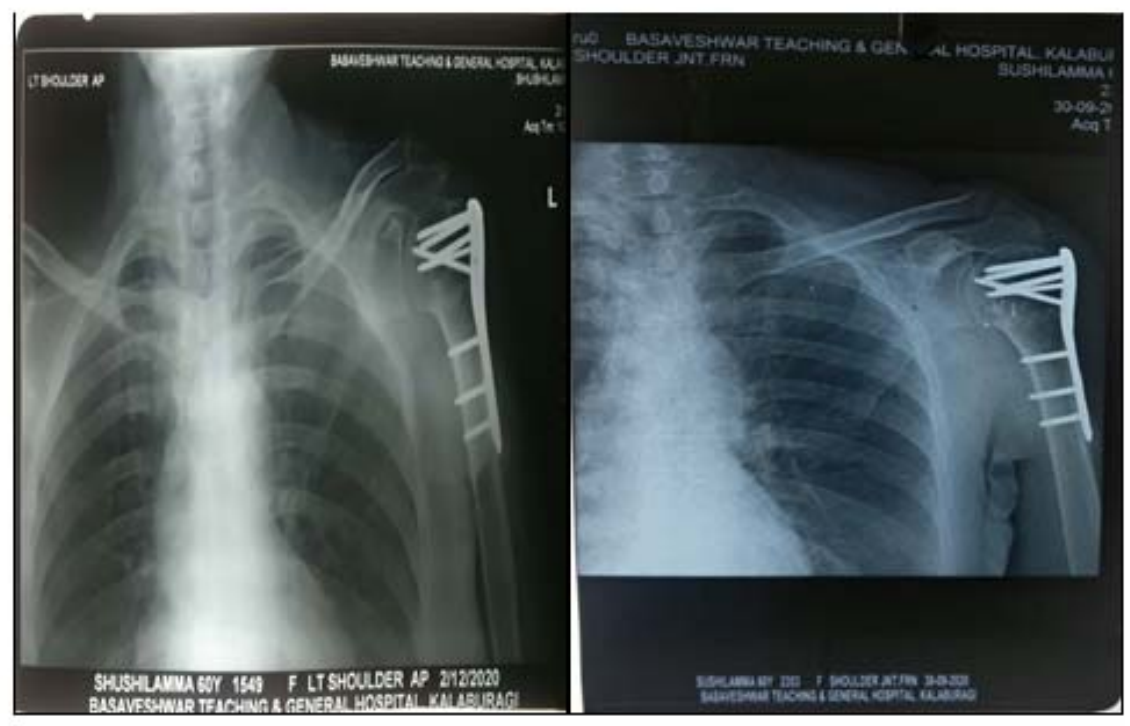

6 month follow up

12 month follow up

\section{Results}

In our study of 20 patients who were followed up to 12 months, majority of the patients were males between age group of 25-85 years (Mean age of 55 years). Right shoulder was more involved, with road traffic accident related injuries was the common mode of injury.

\begin{tabular}{|c|c|c|}
\hline \multirow{2}{*}{ Parameter } & \multicolumn{2}{|c|}{ Total number of cases (20) } \\
\cline { 2 - 3 } & Number & Percentage \\
\hline \multicolumn{3}{|c|}{ Age Distribution (years) } \\
\hline $19-25$ & 3 & $15 \%$ \\
\hline $26-45$ & 7 & $35 \%$ \\
\hline $46-85$ & 10 & $50 \%$ \\
\hline Male & 15 & $75 \%$ \\
\hline Female & 5 & $25 \%$ \\
\hline \multicolumn{2}{|c|}{ Side Distribution } \\
\hline Right & 16 & $80 \%$ \\
\hline Left & 4 & $20 \%$ \\
\hline \multicolumn{2}{|c|}{ Mode of Injury } \\
\hline Fall from height & 7 & $35 \%$ \\
\hline Others & 11 & $55 \%$ \\
\hline \multicolumn{2}{|c|}{2} \\
\hline
\end{tabular}

According to Neer's Scoring System, out of 20 patients, 13 had excellent results, 6 had satisfactory results and 1 had unsatisfactory result.

In our series, 1 patient developed varus collapse and 1 patient had superficial wound infection which was treated by oral antibiotics.

\section{Discussion}

Treatment of fracture dislocation have been evolved over time from conservative to closed reduction by $\mathrm{k}$-wiring to open reduction and internal fixation with locking plate to prosthetic replacement.

Our study was done on 20 patients who had fracture dislocation who underwent ORIF with PHILOS plating. Moonot et al. demonstrated no significant difference in functional outcome between those below and those above 65 years of age at a mean follow-up of 1 months post PHILOS plate fixation ${ }^{[10]}$. However in our study we had significantly inferior clinical outcome in patients over 65 years of age.

The humeral head receives its blood supply from the anterior circumflex artery and its ascending branch the acruate artery $[7,8]$. Additionally, it also is supplied by vessels entering the 
posteromedial region of the proximal humerus, the metaphyseal vessels and the vessels of the greater and lesser tuberosities. These arteries anastomose in the head providing redundant blood supply to the head. Brooks noted that even four-part fractures had blood flow if a portion of the medial calcar was attached to the head fragment ${ }^{[8]}$.

Hertel et al. confirmed this with laser Doppler flowmetry and found that if the head fragment included at least $8 \mathrm{~mm}$ of medial calcar the risk of AVN was significantly decreased due to the preserved blood supply ${ }^{[9]}$ Hertel also showed that AVN could be anticipated $97 \%$ of the time if the patient had a fracture at the anatomical neck, short medial calcar, and a disruption of the medial periosteal hinge.

In order to achieve optimum fixation and achieve maximum stability the implant should be of low profile, preferably anatomical in shape with provision of locking screws and additional holes for repair and restoration of rotator cuff anatomy. The proximal humerus locking plate used in our study had the possible advantages of being low profile, anatomical and providing stable fixation and angular stability due to locking screws. The provision of convergent and divergent screws provided additional stability in presence of comminution and osteoporosis. Provision of suture holes made it easy to repair the rotator cuff and provide stabilization of greater and lesser tuberosity fragment ${ }^{[11]}$. The current recommendation for open reduction and internal fixation is an angulation of more than 45 degree and displacement of more than $1 \mathrm{cms}$. Also it is indicated in displaced unstable fractures with or without dislocation.

Displaced three part and four part fractures with dislocation alter the articular congruity and have a high chance of disruption of blood supply to proximal humerus leading to osteonecrosis. Whenever possible osteosynthesis is the preferred option employed since functional results of hemiarthroplasty are not sufficiently satisfactory in most of the cases ${ }^{[12]}$. Aim of osteosynthesis is to provide stability and adequate repair of rotator cuff is of paramount importance to promote early mobilization.

Yang et al. had an overall complication rate of $35.9 \%$ with screw cut out rate of $7.6 \%{ }^{[13]}$. Helwig et al. had screw penetration in 11 out of 87 cases with an incidence of $12.6 \%$ [14]. Thanasas et al. had a screw cut out rate of $11.6 \%$ in their review of 791 cases ${ }^{[15]}$. Kettler et al. had 24 cases of screw penetration out of 176 cases with incidence of $13.63 \%{ }^{[16]}$. In our study we did not encountered any screw cut out or penetration complication, and had one case of varus collapse. Avascular necrosis is one of the most feared complication following open reduction and internal fixation and can be seen as late as and upto 5 years after injury ${ }^{[17]}$. The incidence of avascular necrosis varies from $0 \%$ to $68 \%$ in different studies [18, 19]. The fracture type itself, dorso-medial comminution and restoration of medial hinge were important and relevant predictors of humeral head necrosis as per study of Jost et al. ${ }^{[20]}$, who in their series had a rate of as high as $68 \%$. This could be because their study included 3 and 4 part fractures only. There was no incidence of avascular necrosis in our study.

The incidence of superficial or deep infection ranges from $0 \%$ to $5 \%$ in different studies ${ }^{[21]}$. There was one case of superficial wound infection noted in our study group.

\section{Conclusion}

On the basis of this study, we concluded that 3 part and 4 part fracture dislocation of proximal humerus treated with ORIF with PHILOS plating as a primary mode of treatment is a safe and effective method even in elderly (i,e $>75$ years of age) with severe osteoporosis this method of fixation/stabilisation of fractures has given excellent results \& with minimal incidence of complications. In our study, all patients had significant relief of pain, had good functional range of motion of shoulder and overall satisfaction.

\section{References}

1. Palvanen M, Kannus P, Niemi S, Parkkari J. Updates in the epidemiology of proximal humeral fractures. Clin Orthop 2006;442:87-92

2. Spence RJ. Fractures of proximal humerus. Curr Opin Orthop 2003;14:269-80

3. Rockwood. Green's fracture in adults; 7th edition proximal humerus fractures by C. Michael Robinson.

4. Hawkins RJ, Bell RH, Gurr K. The three-part fracture of the proximal part of the humerus. Operative treatment. J Bone Joint Surg Am [Internet]. 1986 Dec [cited 2018;68(9):1410-4. Available from: http://www.ncbi.nlm.nih.gov/pubmed/3782213

5. Ko JY, Yamamoto R. Surgical treatment of complex fracture of the proximal humerus. Clin Orthop Relat Res [Internet]. 1996 Jun [cited] 2018;(327):225-37. Available from: http://www.ncbi.nlm.nih.gov/pubmed/8641068

6. Robinson CM, Page RS. Severely impacted valgus proximal humeral fractures. Results of operative treatment. J Bone Joint Surg Am [Internet]. 2003 Sep [cited] 2018;85-A(9):1647-55. Available from: http://www.ncbi.nlm.nih.gov/pubmed/12954821

7. Meyer C, Alt V, Kraus R, Giebel G, Koebke J, Schnettler $\mathrm{R}$, et al. The arteries of the humerus and their relevance in fracture treatment [in German] Zentralbl Chir 2005;130(6):562-567. [Abstract] [Google Scholar]

8. Brooks CH, Revell WJ, Heatley FW. Vascularity of the humeral head after proximal humeral fractures. An anatomical cadaver study. J Bone Joint Surg $\mathrm{Br}$ 1993;75(1):132-6. [Abstract] [Google Scholar]

9. Hertel R, Hempfing A, Stiehler M, Leunig M. Predictors of humeral head ischemia after intracapsular fracture of the proximal humerus. J Shoulder Elbow Surg 2004;13(4):427-33. [Abstract] [Google Scholar]

10. Moonot P, Ashwood N, Hamlet M. Early results for treatment of three- and four-part fractures of the proximal humerus using the PHILOS plate system. J Bone Joint Surg Br [Internet]. 2007 Sep [cited 2018; 89B(9):1206-9. Available http://www.ncbi.nlm.nih.gov/pubmed/17905959

11. Orthop A, Kilic B, Uysal M, Cinar BM, Ozkoc G, Demirors $\mathrm{H}$, et al. ACTA ORTHOPAEDICA et TRAUMATOLOGICA TURCICA Early results of treatment of proximal humerus fractures with the PHILOS locking plate Proksimal humerus kırıkların PHILOS plağı ile tedavisinde erken dönem sonuçlarımız [Internet]. Traumatol Turc. 2008 [cited] 2018, 42. Available

from: http://aott.org.tr/files/journals/1/articles/1736/public/1736 -1938-1-PB.pdf

12. Iannotti JP, Ramsey ML, Williams GR, Warner JJ. Nonprosthetic management of proximal humeral fractures. Instr Course Lect [Internet]. 2004 [cited] 2018;53:403-16. Available from: http://www.ncbi.nlm.nih.gov/pubmed/15116630

13. Yang H, Li Z, Zhou F, Wang D, Zhong B. A Prospective Clinical Study of Proximal Humerus Fractures Treated With a Locking Proximal Humerus Plate. J Orthop 
Trauma [Internet]. 2011 Jan [cited] 2018;25(1):11-7. Available from:

http://www.ncbi.nlm.nih.gov/pubmed/21085030

14. Helwig P, Bahrs C, Epple B, Oehm J, Eingartner C, Weise $\mathrm{K}$, et al. Does fixed-angle plate osteosynthesis solve the problems of a fractured proximal humerus? A prospective series of 87 patients. Acta Orthop [Internet]. 2009 Feb [cited] 2018;80(1):92-6. Available from: http://www.ncbi.nlm.nih.gov/pubmed/19297792

15. Thanasas C, Kontakis G, Angoules A, Limb D, Giannoudis P. Treatment of proximal humerus fractures with locking plates: A systematic review. J Shoulder Elb Surg [Internet]. 2009 Nov [cited] 2018;18(6):837-44. Available from: http://www.ncbi.nlm.nih.gov/pubmed/19748802

16. Kettler M, Biberthaler P, Braunstein V, Zeiler C, Kroetz $\mathrm{M}$, Mutschler W, et al. Die winkelstabile Osteosynthese am proximalen Humerus mit der PHILOS-Platte. Unfallchirurg [Internet]. 2006 Dec [cited] 2018;109(12):1032-40. Available from: http://www.ncbi.nlm.nih.gov/pubmed/17058058

17. Patel S, Colaco HB, Elvey ME, Lee MH. Post-traumatic osteonecrosis of the proximal humerus. Injury [Internet]. 2015 Oct [cited] 2018;46(10):1878-84. Available from: http://www.ncbi.nlm.nih.gov/pubmed/26113032

18. Grawe B, Le T, Lee T, Wyrick J. Open Reduction and Internal Fixation (ORIF) of Complex 3- and 4-Part Fractures of the Proximal Humerus. Geriatr Orthop Surg Rehabil [Internet]. 2012 Mar 19 [cited] 2018;3(1):27-32. Available from: http://www.ncbi.nlm.nih.gov/pubmed/23569694

19. Acklin YP, Stoffel K, Sommer C. A prospective analysis of the functional and radiological outcomes of minimally invasive plating in proximal humerus fractures. Injury [Internet]. 2013 Apr [cited] 2018;44(4):456-60. Available from: http://www.ncbi.nlm.nih.gov/pubmed/23043975

20. Jost B, Spross C, Grehn H, Gerber C. Locking plate fixation of fractures of the proximal humerus: analysis of complications, revision strategies and outcome. J Shoulder Elb Surg [Internet]. 2013 Apr [cited 2018;22(4):542-9. Available from: http://www.ncbi.nlm.nih.gov/pubmed/22959524

21. Bansal V, Sohal H, Bhoparai R. Philos Plate in Proximal Humerus Fracture-Its Functional Outcome and Complications. Int J Orthop [Internet]. 2015;2(3):317-22. Available from:

http://www.ghrnet.org/index.php/ijo/article/view/985 